\title{
Available assays for serum thyroxine and for serum uptake tests
}

\author{
D. B. HORN \\ From the Department of Clinical Chemistry, Western General Hospital, Edinburgh
}

While the present tendency may be towards a more dynamic test for thyroid function, there is still a very definite place for the various in-vitro methods. The relative merits of serum protein-bound iodine estimations and total $T_{4}$ estimations have been dealt with in the previous paper (Clark, 1975). The intention here is to deal with the various methods for the latter test and to indicate their usefulness and value. Similar information concerning serum uptake tests will also be discussed. While most emphasis will be laid on those tests available in kit form which can be carried out either in large numbers by mechanized means or in small batches only occasionally, mention must be made of the earlier work in this field.

There are a number of factors that must be considered before a decision is taken as to which test will be introduced into use in a laboratory. The number of tests required and the frequency of carrying out the tests will influence the decision, especially as far as the degree of work simplification or mechanization is concerned. Other factors to be considered are the range of technical expertise available, the necessity for handling and dispensing radioactive material, and the degree of quality control available both in the preparation of reagents and in the performance of the tests to ensure standard and reproducible conditions. Another very important, if not the most important, consideration is the validity of the result as a measure of thyroid status and hence its value to the clinician both in diagnosis and control of therapy. While considerable attention must be paid to these various factors, sight must not be lost of the economic factors which must include the purchase price of reagents or kits, the time spent by the operators, the grade of staff employed, and the capital cost and effective utilization of the equipment.

The ever-increasing financial burden resulting from the introduction of more sophisticated techniques, which so often require expensive equipment, must be borne in mind, especially when such techniques are applied to an ever-widening section of the population. The need for rapid, reliable, and readily performed techniques, which can be mechanized if possible, to provide satisfactory utilization of both expensive equipment and increasingly expensive manpower, may very well influence the decision, and in fact may be the deciding factor if all other things are equal.

With these considerations in mind the methods available for thyroxine $\left(T_{4}\right)$ assay will be discussed.

\section{Serum $\mathbf{T}_{4}$ Methods}

A number of different separative techniques have been employed in attempts to obtain a specific estimation of thyroxine in serum. Among these must be mentioned butanol extraction, column and paper chromatography, electrophoresis, and dialysis. As most of these methods are not adaptable for either the small laboratory or for screening purposes, they will only be mentioned briefly here.

The procedure of butanol extraction was introduced by Man, Kydd, and Peters (1951). While in certain cases it increases the specificity of hormonal iodine estimation, it is still open to the criticism that nearly all the exogenous organic iodidecontaining substances likely to be encountered can still adversely affect the results. Technically, it is not one of the easiest tests to perform and hence could not be considered as a screening test or as a test to be carried out on large numbers of specimens.

The use of column chromatography for the separation of thyroxine, initially described by Gross and Pitt-Rivers (1952) who used keiselguhr, has been modified by a number of workers. Scott $D$ and Reilly (1954) used anion exchange resins, and $\omega$ Blanquet, Meyniel, and Saviol (1960) used both 2 Dowex 1 and Dowex 50. While these techniques, and 0 those using dialysis (Thorson, Wilkins, Schaffrin, Morrison, and MacIntosh, 1972), have been of very : considerable value in the evaluation and study of thyroid function, they do not lend themselves to the more routine testing of thyroid function.

The introduction in 1960 by Ekins of what he $\stackrel{\mathbb{D}}{\varrho}$ termed saturation analysis did much to facilitate the $\overline{2}$ determination of serum $\mathbf{T}_{4}$. In this technique, 
thyroxine is separated from serum by triple butanol extraction and then added to a standard plasma solution containing a tracer quantity of labelled thyroxine. The shift in radioactivity from the globulin to the albumin fraction was measured electrophoretically and thus gave a measure of the total thyroxine added, and hence of the $T_{4}$ present initially in the serum.

A technically similar, but more rapid method, based on the same principle was developed by Murphy and Pattee in 1963 and was termed 'competitive protein-binding analysis'. In this, the $T_{4}$ is separated by a single ethanol extraction and then measured according to its effect on the passage of a standard tracer-T $_{4}$-plasma solution through a Sephadex column. Subsequently the Sephadex column stage was replaced by the use of ion-exchange resin in a test tube. These authors showed that the method was free from the effects of other iodinecontaining compounds or of mercury. This method has been applied by a number of commercial firms who have marketed a range of test kits.

Initially, use was made of the ${ }^{131}$ I label, now superseded by the more stable and more readily counted 125I tracer. This label is incorporated into thyroxine which is then combined with a standard thyroxinebinding protein (TBG) and the $\mathrm{T}_{\mathbf{4}}$ extracted from the test serum is added. The important requirement in all of the kit tests is a simple and reproducible method of separating the TBG-bound thyroxine after equilibrium has been obtained. This is achieved by different means in the four kits most widely used at present which are Tetrasorb $\mathrm{T}_{4}{ }^{1}$, Resomat $\mathrm{T}_{4}{ }^{2}$, Thyopac- $4^{3}$, and Tetralute ${ }^{4}$. The two former kits employ ion-exchange resins in slightly different forms and the two latter employ Sephadex. In the Tetrasorb $\mathbf{T}_{4}$ kit the finely divided ion-exchange resin is dispersed in polyurethane to give, in effect, a resin sponge, whereas Res-O-Mat utilizes an ion-exchange resin embedded in a fibre matrix making a resin strip. Each of these, strip and sponge, ensures the introduction of a standard amount of resin into each test vial and obviates the need for repetitive weighing at this stage. In the Thyopac-4 kit predispensed amounts of Sephadex granules and buffer solution in vials are used, whereas the Tetralute kits provide columns containing a standard amount of Sephadex G25 in alkaline medium.

Three of the kits require initial ethanol extraction of the serum whereas Tetralute does not and the latter can be considered a definite advantage. Of the three kits requiring alcohol extraction, one, Tetrasorb, involves the removal, by evaporation, of the alcohol,

\footnotetext{
${ }^{1}$ Abbott Laboratories

3Radiochemical Centre

'Mallinckrodt

"Ames Laboratories
}

whereas the others, Thyopac- 4 and Res-O-Mat, do not and the alcoholic extract itself is used after the removal of the denatured protein by centrifugation..$^{5}$ Of course, it is essential to determine the extraction efficiency when such a step is included unless, of course, the standard is subjected to the same procedure. This is the case with Thyopac-4 where two standards of desiccated sera of known thyroxine concentrations are provided. With the other two kits, the extraction efficiency is determined as a separate procedure which is repeated at frequent intervals to ensure that standard conditions prevail and to allow correction of the results determined. This adds to the complexity of the test and the application of a further correction factor, suggested by the manufacturers of the Res-O-Mat kit if the extraction efficiency factor does not come within a set range, could lead to complications. It could well be that some factor, perhaps in the serum used, was contributing to the poor extraction and this was not standard throughout all the tests. With Tetralute an extraction procedure is not necessary as the adsorption of $T_{4}$ is effected by the Sephadex in the strongly alkaline conditions and the protein standards included in the procedure will allow for any alteration in adsorptive efficiency.

Radioactive tracer is not included in two of the tests, namely, Tetralute and Tetrasorb, and must be added separately, but it is only in the latter that there is a need to use a means of pipetting as in the former the use of a dropper bottle is suggested. However, greater precision is obtained if a more accurate means of measuring is used. The other two kits provide vials with predispensed quantities of tracer although in these cases it is necessary to measure known aliquots of the same material at a later stage before counting is carried out. Tetralute, on the other hand, while requiring the addition of tracer from a dropper bottle or pipette, has no further stage involving the volumetric measurement of radioactive material and this is a great advantage.

A further consideration is the need for strict control both of temperature during the procedure and of time of equilibration. Both of the resin kits are temperature-sensitive and an indication of the effect of temperature alterations in the Tetrasorb 125I kit is shown in figure 1 . The effects of temperature are less upon the Sephadex-containing methods and, as long as the temperature does not vary by more than a degree or two, little or none is detectable.

It is obvious from the figure that there is consider-

'Ethanol at room temperature has recently been shown to extract from serum a thyroxine-binding factor, probably TBG, which produces low results by CPBA unless the standards are in serum and extracted similarly. See Goldie et al (J. clin. Path., 1974, 27, 74) and Irvine (J. clin. Endocr., 1974, 38, 468). ED. 


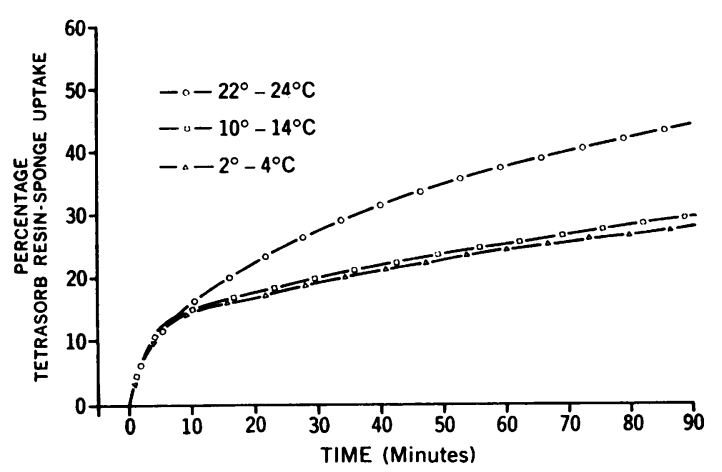

Fig Graph of time/temperature effect on uptake.

able effect of time upon the adsorption of free $T_{4}$ when using the Tetrasorb resin sponge, and the effect on the uptake of the Res-O-Mat strips is similar. It is essential, therefore, to control strictly the time of contact of the strip or sponge with the reaction mixture. With the Sephadex systems, the adsorbent binds thyroxine reversibly and a steady state is rapidly established. It is not essential, therefore, for accurate control of any stage of the procedure although in the Tetralute method the use of sintered discs in the column effects a means of control of the elution time.

Some idea of the relative cost of the various kits can be obtained from table I, which also indicates the time required to complete the test. The actual costs will vary but the relative costs are likely to remain about the same.

\begin{tabular}{llc}
\hline Test & Cost & Time Required $(\mathrm{hr})$ \\
\hline Tetrasorb 125 & $£ 0 \cdot 80 /$ test & $1 \frac{1}{2}-2$ \\
Res-O-Mat T, & $£ 0 \cdot 83 /$ test & $1 \frac{1}{2}-2$ \\
Thyopac-4 & $£ 0 \cdot 57 /$ test & $1-1 \frac{1}{2}$ \\
Tetralute & $£ 0 \cdot 75 /$ test & $1-1 \frac{1}{2}$ \\
\hline
\end{tabular}

Table I Comparison of commercial kits for $T_{4}$ assay

All the kits have the advantage that they are subject to stringent quality control by the manufacturer, and this is a considerable advantage as greater effort can be directed towards the maintenance of good control within the laboratory in the performance of the tests.

The precision of analyses using the four kits shows little difference in this laboratory and both the within-batch and between-batch coefficients of variation of all the kits has been shown to be $5 \%$ or less with both normal and elevated values (D. B. Horn, unpublished data). This figure agrees well with those of Watson and Lees (1973), except that these authors obtained poorer precision with the Res-O-Mat kit.

Finally, there is the consideration of the number of times that each specimen must be counted which, of course, contributes to the overall procedure time. All of the methods require two counts except Thyopac-4 where one count has been shown to be quite satisfactory. It is of interest to compare the number of precision pipettings of solutions required in the various kits. The two kits using resin require three such steps, the Tetralute kit only two, and the Thyopac-4 requires four.

When all the factors mentioned above have been taken into consideration, it is obvious that Thyopac-4 has a number of advantages over the other techniques and can well be recommended at the present time. It must be borne in mind, however, that Tetralute, although it has a number of disadvantages, has the great advantage in that the columns can be re-used on a number of occasions and this in itself results in a lower cost per test.

\section{Serum Uptake Tests}

As triiodothyronine is the labelled hormone usually (but not necessarily) employed in these tests, it has been customary to refer to these tests as ' $\mathrm{T}_{3}$-uptake tests' or, more briefly, as ' $\mathrm{T}_{3}$ tests'; as a result there is a great danger of confusion with $\stackrel{\perp}{\circ}$ tests which actually measure triiodothyronine. $\vec{\overrightarrow{ }}$ It is essential, therefore, to be precise in this respect 3 and always refer to them as 'serum uptake tests' to prevent possible confusion. ${ }^{1}$

The use of the uptake of labelled triiodothyronine by red cells as a means of assessing thyroid function? was introduced by Hamolsky, Stein, and Freedberg 3 in 1957, and it is accepted that this is not a means of actually measuring the concentration of free $\frac{3}{3}$ thyroid hormones themselves. These authors showed that when labelled triiodothyronine was incubated with whole blood it partitioned between the red? cells and plasma in such a way that its uptake by the red cells was related to the thyroid status of $N$ the individual. The uptake was elevated in hyperthyroidism where the circulating levels of thyroid hormone were high and the protein-binding sites relatively saturated, and low in hypothyroidism? where the reverse conditions prevail. In condition such as pregnancy or nephrosis in which there is an increase or a decrease in the maximal TBG capacity; the red cell uptake of $T_{3}$ was found to be low or high respectively. The work of Crispell and Coleman? in 1956 confirmed that the red cell uptake of ${ }^{131} \mathrm{IT} \&$ and ${ }^{131} \mathrm{IT}_{4}$ was dependent upon an equilibrium

'See first contribution 'Nomenclature' by G. K. McGowan. ED. 
between these hormones and the binding sites of plasma proteins and of red cells. The red cell uptake of ${ }^{131} \mathrm{IT}_{3}$ was shown by Osorio, Jackson, Gartside, and Goolden in 1961 to be inversely related to the free or unsaturated capacity of TBG as measured by electrophoresis, but it did not correlate with the thyroid-binding pre-albumin (TBPA) capacity. Ingbar (1960) has demonstrated that a greater than normal proportion of $T_{4}$ is associated with the TBG when TBPA capacity is reduced. As a result, less $T_{3}$ can be bound to the TBG and more should be taken up by the red cells. The red cell uptake of ${ }^{131} \mathrm{IT}_{3}$ may indeed be high in the presence of a low TBPA capacity, but this may be attributed to the associated fall in free TBG capacity. The red cell uptake of ${ }^{131} \mathrm{IT}_{3}$ was therefore a potentially useful in-vitro method of assessing thyroid function by indicating the free TBG capacity. While this test was relatively simple to perform it suffered from a number of serious drawbacks. The results were dependent upon the haematocrit, the absence of haemolysis, and also upon the red cell morphology and, although various attempts had been made to correct for these factors, problems still existed. As the uptake is dependent upon the TBG capacity it may also deviate from normal even in the absence of thyroid disease.

The introduction of ion-exchange resins, and later of Sephadex, greatly increased the reproducibility of this type of technique and, as expected, there has been a wide range of variations and modifications introduced. The uptake test using resin instead of red cells was introduced by Mitchell in 1958 and there have been numerous reports of its usefulness in the literature since then. Readers are referred to the very useful review of the literature by Clark in 1966 which also dealt with the other tests such as those involving charcoal adsorption which will not be mentioned here.

The resin uptake test is very similar to that of the red cell uptake test but, in this case, serum is used instead of whole blood. The triiodothyronine used was initially labelled with ${ }^{131}$ I but more recent work has utilized the ${ }^{125} \mathrm{I}$ label. Labelled $T_{3}$ is added to serum and, after an incubation period, the $T_{3}$ not bound by the TBG is absorbed onto an ion-exchange resin. There are a number of advantages of this type of method, not least of which is the replacement of whole blood by serum which can be transported and stored very much better; care must be taken to ensure that no red cells remain in the sera as these would affect the uptake of $T_{3}$. There is a problem that any free labelled inorganic iodide, which tends to be a contaminant of most of the labelled thyroid hormones (especially with the 131 I label), is strongly bound by the resin. Any variation in the degree of the radio-iodide contamination can lead to variations in the percentage uptake of the label by the resin. This effect can be minimized by employing a control standard serum with each batch of estimations and expressing the result in a percentage of the control value. As the use of heparinized plasma may lead to anomalous results, only serum should be used for the estimation.

Proof of the fact that the resin uptake method gives a measure of free TBG capacity was provided in 1965 by the work of Goolden, Gartside, and Osorio who showed a very close correlation between red cell and resin uptake of ${ }^{131} \mathrm{IT}_{3}$. This correlation was demonstrated using ${ }^{131} \mathrm{IT}_{3}$ and the resin sponge used in the Triosorb ${ }^{1}$ kit, and has been confirmed since by other workers. They showed that the rate at which ${ }^{131} \mathrm{IT}_{3}$ is taken up by the resin increases with the concentration of the thyroxine present in the serum. They concluded that the red cell method measures the final equilibrium between the red cells and the plasma proteins whereas the resin method is really a measure of the speed with which $T_{3}$ becomes irreversibly bound to the resin. When one considers the nature of the linkages between the resin and $T_{3}$ this is not unexpected. As a result the duration of the incubation with resin is very important. They also showed that the resin uptake test is sensitive to temperature changes and that there is an increase in the uptake of ${ }^{131} \mathrm{IT}_{3}$ by the resin as the incubation temperature rises.

The introduction of the use of Sephadex in 1966 marked a considerable step forward as the uptake of inorganic iodine by this is minimal and one of the major objections to the use of this type of test was overcome. The more ready availability of the $125 \mathrm{I}$ label did much to make this problem of inorganic iodide contamination less important as the degree of contamination of this label was much less than that of ${ }^{131} I$.

The four kits most widely used at present are Triosorb ${ }^{1}$, Res-O-Mat $\mathrm{T}_{3}{ }^{2}$, Thiopac- $3^{3}$, and Trilute ${ }^{4}$. The first two kits use ion-exchange resins as described previously for the $T_{4}$ kits, whereas both Thiopac-3 and Trilute use Sephadex. The separate addition of radioactive tracer is required in both the Triosorb and Trilute tests and, while the use of a dropper bottle is suggested in the latter, greater precision is obtained if a pipette is used. The radioactive tracer is predispensed in the other two kits but as it must be sampled at a later stage there is nothing to choose between the kits in respect of pipetting.

\footnotetext{
${ }^{1}$ Abbott Laboratories

Mallinckrodt

'Radiochemical Centre (Amersham)

A Ames Laboratories.
} 
The resin kits are both temperature and time dependent (Goolden et al, 1965) in the same way as the resin-based $T_{4}$ tests. Sephadex kits do not suffer from this problem to the same extent. It should be noted that the problem can be overcome if timing and temperature are strictly standardized.

When considering the usefulness of a test in the laboratory the number of precision pipettings to be carried out can influence the decision unless, of course, mechanized means are used for this. The number of such precision pipetting steps that are required in the various tests are as follows; two for Triosorb, two for Thiopac, one for Res-O-Mat, and one for Trilute, although better precision is obtained in the latter if two are carried out.

The times required to carry out the tests vary considerably as the two using Sephadex take approximately $\mathbf{3 0}$ minutes to complete whereas the time for the resin tests is much longer-approximately 90 minutes for Triosorb and 150 minutes for Res-O-Mat 3.

All of the kits have the advantage that they are subject to strict quality control during manufacture, and the user may concentrate on the control of quality procedures left to the laboratory. However, it is possible, by means of automatic dispensers of either Sephadex or resin, to reproduce in the laboratory as accurate and sometimes more accurate dispensing of these substances than is obtained in commercial kits. In our laboratory the coefficient of variation obtained by a skilled operator for the four test kits was less than $4 \%$ in each case and this compared with a coefficient of variation of $2 \%$ for our own resin method using our own reagents. Under routine conditions the coefficient of variation for the current period in our department, using the same resin method, is $5 \%$ at a normal value. Automatic dispensers are used to measure the critical volumes and the resin is dispensed by a plastic dispenser that delivers $300 \pm 10 \mathrm{mg}$ resin using a 'coin in a horizontal slot' technique from a small hopper.

The relative costs of the four tests are shown in table II where it will be seen that Thiopac-3 has the lowest cost per test, which is a good recommendation especially when the test has such a good coefficient of variation, reasonable shelf life, and has been

\begin{tabular}{ll}
\hline Test & Cost \\
\hline Thyopac 3 & $£ 0 \cdot 50 /$ test \\
Triosorb & $£ 0 \cdot 62 /$ test \\
Res-O-Mat $\mathrm{T}_{3}$ & $£ 0.62 /$ test \\
Trilute & $£ 0.60 /$ test \\
\hline
\end{tabular}

Table II Cost of commercial kits for serum uptake tests

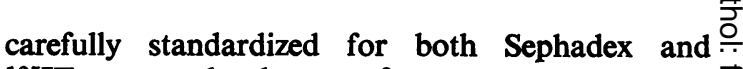
${ }_{125} \mathrm{IT}_{3}$ content by the manufacturers.

In a large department where many tests are being carried out, the economic advantage of the use of kits is not so obvious, especially as the adsorbent $\frac{\overline{\bar{N}}}{\bar{D}}$ can be dispensed automatically, accurately, and $\vec{\nabla}$ relatively cheaply, and as the dispensing of ${ }^{125} \mathrm{IT}_{3} \propto$ does not present any difficulty. However, except $\stackrel{0}{\circ}$ where very large numbers of tests are to be carried $\vec{\circ}$ out there is really little to be gained by not using test kit methods, apart of course from personal $\vec{\omega}$ satisfaction.

Perhaps it should be mentioned at this point? that the washing of the resin sponge required in the Triosorb method could be considered a disadvantage $\omega$ when handling large numbers of specimens.

\section{Calculation and Presentation of Results}

It is essential to have a clear understanding of the method of presentation of results as this is by no $\stackrel{\vec{T}}{\mathcal{T}}$ means uniform for the various serum uptake test $\overrightarrow{\vec{\varphi}}$ methods. It is unfortunate that a standard method $\bullet$ has not been adhered to in this respect as the present system can cause misunderstanding. The various methods of reporting serum uptake results are shown in table III. It should be noted that the red $\overline{0}$ cell method used initially was reported as the per- $\stackrel{0}{\not}$ centage of the activity that was bound to the red $\stackrel{\unrhd}{\unrhd}$ cells, and many of the original resin methods used $\overrightarrow{\overrightarrow{0}}$ a similar system. Subsequently Clark (1963) intro- $\frac{3}{3}$ duced a fraction calculated from the resin uptake $\vec{\partial}$ ratio where the results were expressed as the ratio of the resin uptake for the test specimens to the uptake for a control pool of normal sera.

Both the Triosorb and Trilute results are expressed $\frac{\sigma}{3}$ as percentage uptake by the adsorbent whereas the Thiopac-3 and Res-O-Mat values are based on the $\frac{\rho}{3}$ ratio of activity bound by the patient's own serum proteins to that bound by the pool of normal $\frac{}{2}$ human serum, the former being expressed as $\frac{D}{O}$ a percentage and the latter as a fraction (with a correction factor for each batch of control serum). N The scale of values for tests based on serum uptake is the reverse of that for tests based on uptake by $\mathrm{N}$ adsorbents, ie, high instead of low values for $\omega$ hypothyroidism, low instead of high for hyper- $\mathcal{O}$ thyroidism (table III). Therefore, when serum uptake $\varrho$ tests are referred to, it is essential to give not only $\Phi$ the reference range but also to state whether a raised $\stackrel{?}{+}$ value indicates hyper- or hypothyroid status. ${ }^{1}$

As nearly all the serum thyroxine is bound to $\stackrel{\vec{D}}{\vec{D}}$ protein and physiologically inactive, the serum

${ }^{1}$ See recommendations for standardization of serum uptake tests in $\sigma$ contribution on Nomenclature, and its appendix on the free thyroxine index, by G. K. McGowan. ED. 


\begin{tabular}{|c|c|c|c|c|}
\hline \multirow[t]{2}{*}{ Method } & \multirow[t]{2}{*}{ Calculation } & \multicolumn{3}{|c|}{ Thyroid Status } \\
\hline & & Hуро- & Normal & Hyper- \\
\hline Hamolsky & $\frac{\text { Activity bound to } \mathbf{R B C}}{\text { Total activity }} \times 100$ & $<15$ & $15-20$ & $>20$ \\
\hline Clark & $\frac{\text { Activity bound to resin }}{\text { Total activity }} \times 100=\% \mathrm{RU} \rightarrow \frac{\% \mathrm{RU}(\mathrm{Pt})}{\% \mathrm{RU}(\text { Control) }}$ & $<0.82$ & $0 \cdot 82-1 \cdot 28$ & $>1.28$ \\
\hline Triosorb & $\frac{\text { Activity bound to resin }}{\text { Total activity }} \times 100$ & $<23$ & $23-33$ & $>33$ \\
\hline Trilute & $\frac{\text { Activity bound to Sephadex }}{\text { Total activity }} \times 100$ & $<38$ & $42-58$ & $>62$ \\
\hline Res-O-Mat & $\frac{\text { Activity bound to serum sites (pt) }}{\text { Activity bound to serum sites (control) }} \times \mathrm{F}$ & $>1 \cdot 13$ & $0 \cdot 87-1 \cdot 13$ & $<0.87$ \\
\hline Thyopac-3 & $\frac{\text { Activity bound to serum sites (pt) }}{\text { Activity bound to serum sites (control) }} \times 100$ & $>117$ & $92-117$ & $<92 \%$ \\
\hline
\end{tabular}

Table III Various methods of reporting serum uptake test results

\begin{tabular}{|c|c|c|c|}
\hline Method & Calculation & Nomenclature & Reference Range \\
\hline Clark and Horn & RUR $\times$ PBI value & FTI (free thyroxine index) & $2 \cdot 2-7 \cdot 08$ \\
\hline McLagan and Howorth & $\mathbf{R U R} \times \mathbf{T}_{\mathbf{4}}$ value & $T_{4}$-FTI & $4 \cdot 5-11 \cdot 5$ \\
\hline Radiochemical Centre (a) & $\frac{\text { PBI value }}{\text { Thyopac-3 value }}$ & FTI & $3 \cdot 4-8 \cdot 6$ \\
\hline Radiochemical Centre (b) & $\frac{\text { Thyopac- } 4 \text { value }}{\text { Thyopac- } 3 \text { value }} \times 100$ & Free Thyopac index & $5 \cdot 7-13 \cdot 2$ \\
\hline Abbott Laboratories & $\frac{\text { Triosorb \% uptake }}{100} \times$ Tetrasorb value & T7 & $1 \cdot 4-4 \cdot 6$ \\
\hline Mallinckrodt & $\frac{\text { Res-O-Mat } \mathrm{T}_{4} \text { value }}{\text { Res-O-Mat } \mathrm{T}: \mathrm{TBC} \text { index }}$ & Res-O-Mat FT،I & $4 \cdot 4-15 \cdot 7$ \\
\hline
\end{tabular}

Table III Various free thyroxine indices

uptake test has been used to 'correct' the total $\mathrm{T}_{4}$ level in order to obtain an indication of the free physiologically active $T_{4}$ concentration. Some of these derived values are shown in table IV.

The product of protein-bound iodine and the serum resin uptake ratio was proposed as the 'free thyroxine index'1 (Clark and Horn, 1965) and the reference range was, as shown, $2 \cdot 2$ to $7 \cdot 08$. Values less than $2 \cdot 2$ are indicative of hypothyroidism whereas values greater than 7.08 are found in hyperthyroidism. The various modifications and improvements introduced to take account of more accurate methods of thyroxine estimation have resulted fortunately in values which are less confused than those for the uptake methods from which they are derived. There is still quite a difference in the reference ranges quoted but at least a value less than the lower quoted reference value has the same meaning in each case and this greatly facilitates interpretation of the results.

There is much to be said for the use of one of the derived values such as the 'free thyroxine index'

${ }^{1}$ See appendix to contribution on nomenclature by G. K. McGowan. ED. as an indication not only of the circulating thyroid hormone concentration but also of the thyroxine binding proteins. Such an index provides the clinician with the best single measure of thyroid status currently available in most hospitals.

References

Blanquet, P., Meyniel, G., and Savoie, J. C. (1960). Ion exchange resins and thyroid metabolism. C.R. Acad. Sci. (Paris)., 250, 217-219.

Clark, F. (1963). Resin uptake of ${ }^{131}$ I-triiodothyronine: an in vitro test of thyroid function. Lancet, 2, 167-169.

Clark, F. (1967). The estimation of thyroid hormone binding by plasma proteins and of unbound levels of thyroxinein in plasma. J. clin. Path., 20, 344-351.

Clark, F., and Horn, D. B. (1965). Assessment of thyroid function by the combined use of the serum protein-bound iodine and resin uptake of ${ }^{131}$ I-triiodothyronine. J. clin. Endocr., 25, 39-45.

Crispell, K. R., and Coleman, J. (1956). A study of the relative binding capacity of plasma proteins, intact human red cells and human red cell stroma for radioactive $I^{131}$ labeled $L$ thyroxine. J. clin. Invest., 35, 475-480.

Ekins, R. P. (1960). The estimation of thyroxine in human plasma by an electrophoretic technique. Clin. chim. Acta, 5, 453-459.

Goolden, A. W. G., Gartside, J. M., and Osorio, C. (1965). An evaluation of the ${ }^{131}$ I-triiodothyronine resin sponge test. J. clin. Endocr., 25, 127-133.

Gross, J., and Pitt-Rivers, R. (1952). The identification of 3:5:3'L-Triiodothyronine in human plasma. Lancet, 1, 439-441.

Hamolsky, M. W., Stein, M., and Freedberg, A. S. (1957). The thyroid hormone-plasma protein complex in Man. II. A new 
in vitro method for study of 'uptake' of labelled hormonal components by human erythrocytes. J. clin. Endocr., 17, 33-44.

Ingbar, S. H. (1960). The interaction of the thyroid hormones with the proteins of human plasma. Ann. New York Acad. Sci., 86, 440-453.

Man, E. B., Kydd, D. M., and Peters, J. P. (1951). Butanol-extractable iodine of serum. J. clin. Invest., 30, 531-538.

Mitchell, M. L. (1958). Resin uptake of radiothyroxine in sera from non-pregnant and pregnant women. J. clin. Endocr., 18, 14371438.

Murphy, B. E. P., and Pattee, C. J. (1964). Determination of thyroxine utilizing the property of protein binding. J. clin. Endocr., 24, 187-196.
Osorio, C., Jackson, D. J., Gartside, J. M., and Goolden, A. W. G.으 (1961). The uptake of ${ }^{181}$ I triiodothyronine by red cells in relation to the binding of thyroid hormones by plasma proteins. $\overline{\bar{c}}$ Clin. Sci., 21, 355-365.

Scott, K. G., and Reilly, W. A. (1954). Use of anionic exchange resin $O$ for the determination of protein-bound $I^{131}$ in human plasma. $\bar{O}$ Metabolism, 3, 506-509.

Thorson, S. C., Wilkins, G. E., Schaffrin, M., Morrison, R. T., and $\frac{\mathcal{\sigma}}{\partial}$ McIntosh, H. W. (1972). Estimation of serum-free thyroxine $\mathbb{D}$ concentration by ultrafiltration. J. Lab. clin. Med., 80, 145-154.

Watson, D., and Lees, S. (1973). Comparative study of thyroxine assays employing kit radio-ligand reagents. Ann. clin. Biochem., $\rightarrow$ 10, 14-22.

\section{Reports and Bulletins prepared by the Association of Clinical Biochemists}

The following reports and bulletins are published by the Association of Clinical Biochemists. They may be obtained from The Publishing Department, British Medical Journal (ACB Technical Bulletins), B.M.A. House, Tavistock $\infty$ Square, London WC1H 9JR. Overseas readers should remit by British Postal or Money Order.

SCIENTIFIC REPORTS (price $£ 1 \cdot 00 / \$ 2.00$ each)

3 Automatic Dispensing Pipettes: an assessment of 35 commercial instruments September 1967 P. M. G. BROUGHTON, A. H. GOWENLOCK, G. M. WIDDOWSON, and K. A. AHLQUIST

4 An Evaluation of five Commercial Flame Photometers suitable for the Simultaneous Determination of Sodium and Potassium March 1970 P. M. G. BROUGHTON and J. B. DAWSON

SCIENTIFIC REVIEWS (price $£ 1 \cdot 00 / \$ 2.00$ each)

1 The Assessment of Thyroid Function March 1971 F. V. FLYNN and J. R. HOBBS

2 Renal Function Tests Suitable for Clinical Practice January 1972 F. L. MITCHELL, N. VEALL, and R. W. E. WATTS

TECHNICAL BULLETINS (price $₫ 1 \cdot 00 / \$ 2.00$ each)

9 Determination of Urea by AutoAnalyzer November 1966 RUTH M. HASLAM

11 Determination of Serum Albumin by AutoAnalyzer using Bromocresol Green October 1967 B E. NORTHAM and G. M. WIDDOWSON

13 An Assessment of the Technicon Type II Sampler Unit March 1968 B. C. GRAY and G. K. McGOWAN 14 Atomic Absorption Spectroscopy: an outline of its principles and a guide to the selection of instruments May 1968 J. B. DAWSON and P. M. G. BROUGHTON

15 A Guide to Automatic Pipettes (2nd edition) June 1968 P. M. G. BROUGHTON

16 A Guide to Automation in Clinical Chemistry May 1969 P. M. G. BROUGHTON

17 Flame Photometers: a comparative list of 17 instruments readily available in Britain August 1969 P. WIIDING

19 Spectrophotometers: a comparative list of low-priced instruments readily available in Britain May 1970 C. E. WILDE and P. SEWELL

20 Quantities and Units in Clinical Biochemistry June 1970 P. M. G. BROUGHTON
21 Filter Fluorimeters: A comparative list of 18 instru- $\vec{\infty}$ ments September 1970 H. BRAUNSBERG and s. s.o BROWN

22 Bilirubin Standards and the Determination of Bilirubin by Manual and Technicon AutoAnalyzer Methods $\bar{\supset}$ January 1971 BARBARA BILLING, RUTH HASLAM, and N. WALD

23 Interchangeable Cells for Spectrophotometers and Fluorimeters September 1971 S. S. BROWN and A. H.O GOWENLOCK

24 Simple Tests to Detect Poisons March 1972 B. w. $\frac{\mathscr{Q}}{\not 2}$ MEADE et al.

\section{Blood Gas Analysers May 1972 K. DixoN}

26 Kits for Enzyme Activity Determination September 1972 S. B. ROSALKI and D. TARLOW

27 Assessment of Pumps Suitable for Incorporation into Existing Continuous Flow Analytical Systems November 1972 A. FLECK et al.

28 Routine Clinical Measurements of Transferrin in Human Serum September 1973 K. DIXON

29 Control Materials for Clinical Biochemistry (5th edition) September 1973 J. F. STEVENS

30 Notes on the Quality of Performance of Serum Cholesterol Assays September 1973 s. S. BROWN 31 Determination of Uric Acid in Blood and in Urine
July 1974 R. W. E. WATTS

32 A Survey of Amino Acid Analyzers Readily Avail able in the United Kingdom September 1974 J. EOC CARLYLE and P. PURKISS

33 Definitions of some Words and Terms used in Automated Analysis November 1974 A. FLECK, R.ROBINSON, S. S. BROWN, and J. R. HOBBS

34 Measurement of Albumin in the Sera of Patients January 1975 LINDA SLATER, P. M. CARTER, and J. RO HOBBS 